\title{
The value of urban green space in Britain: a methodological framework for spatially referenced benefit transfer ${ }^{1}$
}

\author{
Grischa Perino ${ }^{2}$, Barnaby Andrews ${ }^{3}$, Andreas Kontoleon $^{4}$ and Ian Bateman ${ }^{3}$
}

\begin{abstract}
A meta-analysis of studies valuing urban greenspace in the UK is undertaken to yield spatially sensitive marginal value functions. A geographical information system (GIS) is used to apply these functions to spatial data detailing the location of such greenspace resources in five British cities and monetary values are computed. This procedure is repeated for the six future scenarios used in the UK National Ecosystem Assessment and changes in values calculated for the period 2010-60. These findings are then extrapolated to all major British cities to obtain per household and aggregate valuation estimates for each scenario both with and without distributional weights. While subject to a number of shortcomings in both data availability and methodology, this represents the first systematic and comprehensive attempt to value marginal changes in urban greenspace while accounting for spatial heterogeneity.
\end{abstract}

Keywords: UK National Ecosystem Assessment, Urban Greenspace, Spatially Referenced Benefit Transfer

JEL codes: Q51, Q57, R0

\footnotetext{
${ }^{1}$ We thank Olena Talavera for excellent research assistance. The work reported was funded in part by the Social and Environmental Economic Research (SEER) into Multi-Objective Land Use Decision Making project (in turn funded by the Economic and Social Research Council (ESRC); Funder Ref: RES-060-25-0063). This work is based on data provided through EDINA UKBORDERS with the support of the ESRC and JISC and uses boundary material which is copyright of the Crown and the Post Office.

${ }^{2}$ Corresponding author: School of Economics, CBESS and CSERGE, University of East Anglia, Norwich Research Park, Norwich NR4 7TJ, United Kingdom; g.perino@uea.ac.uk

${ }^{3}$ Centre for Social and Economic Research on the Global environment (CSERGE), School of Environmental Sciences, University of East Anglia, Norwich, NR4 7TJ, United Kingdom.

${ }^{4}$ Department of Land Economy, University of Cambridge.
} 


\section{Introduction}

Urban greenspaces, from small community gardens to major parks like Hyde Park in London, not only shape the 'face' of cities but are an important aspect of quality of life to local residents. They provide areas for local recreation, pleasant views, cleaner air and many other amenities. ${ }^{5}$ Although urban greenspaces might appear small in comparison to other habitats in terms of size, the value of the ecosystem services they provide is likely to be disproportionately high due to their location; delivering benefits straight to people's doorsteps. At the same time the provision of urban greenspace involves high opportunity costs as it requires land in areas where it is most valuable. In order to make the correct trade-offs between different urban land uses, it is essential to quantify the value of the ecosystem services provided by urban greenspace. There is a rich and sophisticated literature that tries to do just that. However, it almost exclusively focuses on individual greenspaces (if not individual trees) or single cities.

Our first contribution is to derive what we believe to be the first comprehensive, nationwide and spatially referenced estimates for the value of ecosystem services provided by urban greenspace and to deliver this in a form directly compatible with the UK National Ecosystem Assessment (NEA). To this end we use meta-analyses to derive a set of spatially sensitive marginal value functions for three different types of urban greenspace. Combining these functions with detailed geographical information system (GIS) data on five case study cities, we estimate the change in welfare arising under six NEA scenarios. These findings are then extrapolated to all of Great Britain at the highly detailed, lower super output census area (LSOA) level.

Previous research shows that geographic referencing is vital for transferring values for spatially defined goods since location dictates value and this typically decays over increasing distance (Bateman et al., 2002, 2006). In the case of urban greenspace, the proximity to populations, their density, income levels and the availability of other substitutes all vary with location and are crucial drivers of the value provided by urban greenspace. Our approach is able to take many, though admittedly not all, of these spatial factors into account.

\footnotetext{
${ }^{5}$ The full array of ecosystem services provided by urban greenspace in the UK as well as a discussion of different greenspace definitions and classifications can be found in Davies et al. (2011).
} 
We are aware of only one prior meta-analysis of urban greenspace value. Brander and Koetse (2011) reanalyse a number of prior studies, however their sample relies heavily on US studies and their results indicate that values can differ substantially across regions. The value functions they estimate are therefore not obviously suitable for transferral to Great Britain. Moreover, they conduct two separate meta-analyses, one estimating the impact of greenspace size upon value and the other examining the effects of distance on value. We estimate marginal value functions that explicitly take into account both of these measures.

Our second contribution is to provide a methodological framework that allows the derivation of urban greenspace values at different spatial resolutions in a manner which can readily be applied by policy makers to evaluate current and proposed future land uses. The methodological framework developed through the study permits individual components of the analysis to be updated as data becomes available.

Sensitivity analyses are provided by re-evaluating our results using different discounting regimes and distributional weights. The latter highlights that economically deprived neighbourhoods benefit disproportionately from provision of urban greenspace.

The remainder of this paper is structured as follows. Section 2 applies a meta-analysis to derive marginal value functions for three types of urban greenspace. The urban aspects of the NEA scenarios are outlined in Section 3. Section 4 evaluates the changes implied by scenarios for five UK cities to obtain consequent urban greenspace values. These values are extrapolated to Great Britain in Section 5 and the final section concludes.

\section{Marginal Value Functions}

To allow for the potential of different marginal values attaching to different types of greenspace we divide the total area of urban and peri-urban greenspace into three categories ${ }^{6}$; Formal Recreation Sites, City-Edge Greenspace and Informal Greenspace which we define as follows:

- Formal Recreation Sites (mainly city parks) are defined as accessible greenspaces of at least 1 ha in size and include accessible formal parks (including play parks) and

\footnotetext{
${ }^{6}$ A discussion of different greenspace definitions and classifications and the problems created by the absence of consistent and comprehensive data on UK urban greenspace can be found in Davies et al. (2011).
} 
gardens, accessible recreation grounds, accessible urban woodlands ${ }^{7}$ and certain other highly accessible urban natural areas $^{8}$.

- City-Edge Greenspace is defined as areas of non-developed land directly adjacent to an urban fringe. Their size is assumed to be $10 \mathrm{ha}^{9}{ }^{9}$

- Informal Greenspace is defined as the area designated as 'natural' in official sources ${ }^{10}$. It is measured as the percentage of Informal Greenspace per $1 \mathrm{~km}$ square. ${ }^{11}$

Spatially sensitive valuation functions for each category of greenspace were then developed as discussed below.

\subsection{Estimating marginal value functions for Formal Recreation Sites and City-Edge Greenspace.}

A review of the relevant literature produced a set of five studies ${ }^{12}$ which value Formal Recreation Sites and City-Edge Greenspace in UK cities, from which 61 marginal valuations of proximity to urban greenspace were extracted. These values represent the increase in the property price arising from a reduction of one metre in the distance to the centre of the greenspace area. The studies used in our meta-analysis embrace three different valuation methods: hedonic pricing (two studies giving thirty-seven values), contingent valuation (two studies providing six values) and expert interviews (one study yielding eighteen values).

These valuation estimates were linked to data on the size of the greenspace analysed, the distance from the greenspace centre at which the valuation is taken, median household income in the study area, population of the city and characteristics of the studies themselves such as the elicitation method used. Table 1 presents summary statistics of the data used in the metaanalysis. Note that the dataset includes all relevant UK studies that are deemed to be of sufficient quality and contain the necessary information e.g. on size of the parks valued,

\footnotetext{
${ }^{7}$ As defined in the UK Forestry Commission Woods For People dataset.

${ }^{8}$ As defined in the urban elements of the Natural England CROW access database.

${ }^{9}$ The actual size of City-Edge Greenspace is generally not well specified. The 10ha used corresponds to the average size of a Formal Recreation Site in the sample.

${ }^{10}$ Specifically the Ordnance Survey Mastermap Topographic area layer (scale 1:1250).

${ }^{11}$ This includes the parts coded 'natural' of the two other types of greenspace. This avoids over-stating the marginal value of the 'natural' land cover not part of Formal Recreation Sites or City-Edge Greenspace as they clearly depend on the total amount present in an area. Double counting is only a minor issue as there is only a partial overlap of the ecosystem services provided (directly distance related services versus those related to land use shares) and as the subsequent analysis shows, the contribution of Informal Greenspace is almost negligible compared to the other two categories.

12 Andrews (2009), CabeSpace (2005), Dehring and Dunse (2006), Dunse et al. (2007) and Hanley and Knight (1992).
} 
regardless of whether they find a positive marginal value of proximity to urban greenspace or not.

\section{[INSERT TABLE 1]}

Table 2 presents regression results from the meta-analysis. A full description of the variables can be found in the appendix. The dependent variable is the marginal value of proximity to urban greenspace in pounds per metre. The regression results presented in Table 2 are based on a log-log specification estimated using a Heckman selection model. The log-log specification was used to avoid the heteroskedasticity present in linear version and the Heckman model allowed us to keep observations with zero or negative marginal values in the sample despite the log-log transformation with their valuations being reported as missing. Perino et al. (2011) present and discuss alternative specifications.

Here the lambda parameter is not significantly different from zero providing no evidence of selection bias. The selection stage of the Heckman regression nevertheless provides an interesting insight. Two of the three variables having a significant effect on the probability that a zero or negative marginal value of urban greenspace is reported describe a study's design. Neither the number of observations in a study nor the elicitation method used should have an impact on people's preferences but only on how accurately they can be measured. The zero and negative values reported therefore seem at least to some degree driven by inappropriate study design rather than by subjects' preferences.

The coefficients of the valuation equation in Table 2 are used to specify the marginal value function for proximity to Formal Recreation Sites and City-Edge Greenspace.

\section{[TABLE 2]}

The regression results show that the marginal value of urban greenspace is monotonically decreasing in distance, income and population and monotonically increasing in the size of the Formal Recreation Site. While the results for distance and size are intuitive, those for income and population require further consideration. Marginal values of proximity could be decreasing with income since people with higher income can afford provision and access to substitutes in the form of private gardens and trips to the countryside, respectively. This is reflected in some of the underlying original studies (Dehring and Dunse, 2006; Dunse et al., 
2007) which find the price of flats to be more sensitive to the proximity of greenspace than those for houses. Although it might seem somewhat surprising that this effect appears to dominate the normal good character present for many environmental goods, the absence of a positive relationship between income and the value of urban greenspace is common in the literature (see e.g. Brander and Koetse (2011) and the references therein). It has to be noted that only one of the original studies (Andrews, 2009) reports the income of participants. The income variable was hence generated by using the description of the study area to retrieve data on LSOA-level median household incomes ${ }^{13}$, which clearly is less accurate than if income would have been reported in the original studies. The negative effect of city population on park valuation might be driven by increased crowding of parks in bigger cities.

\subsection{Marginal Value Function for Formal Recreation Sites and City-Edge Greenspace}

The results from the meta-analysis provide distance sensitive marginal value functions which allow us to derive estimates of welfare changes resulting from different policy interventions which affect the size of greenspace, the distance between parks and areas of high population density, and the size of cities.

All studies included in the meta-analysis report one-off payments. Hence, the marginal value functions measure the discounted marginal benefit derived from greenspace proximity over the planning horizon. The functional form implies that the exponent of a variable indicates the percentage increase in the marginal value if the level of this variable is increased by one percent. Hence, a one percent increase in the distance to the centre of the greenspace reduces (because distance appears in the denominator) the marginal value by 0.941 percent. The regression in Table 2 identifies the following basic marginal value function for Formal Recreation Sites and City-Edge Greenspace.

MValue(Distance, Size, Income, Population)

$$
=e^{44.53} \frac{\text { Size }^{0.5}}{\text { Distance }^{0.941} \cdot \text { Income }^{2.945} \cdot \text { Population }^{0.554}} \quad \text { Eq. } 1
$$

The distance decay curve obtained from the marginal value function of Eq 1. is illustrated in Figure 1 (dotted line and right part of the bold line) for a 10 hectare park in a city with a population of 200,000 and a household with an income of $£ 25,000$. To correct for the fact that

\footnotetext{
${ }^{13}$ Obtained from the Experian Mosaic data set.
} 
geometric postcode centroids can fall within park boundaries and the marginal value function is based on the distance to the centre, the following adjustment is applied for Formal Recreation Sites.

\author{
MValueFRS $=$ MIN [ \\ MValue(Distance, Size, Income, Population), \\ MValue $(100 *($ Size/3.14)^0.5, Size, Income, Population)]
}

Eq. 2

This adjustment is illustrated by the bold line in Figure 1 and caps the left part of the marginal value function at a distance from the centre of the site that is equivalent to the radius of a circle with the same area as that of the park.

\title{
[FIGURE 1]
}

For City-Edge Greenspace the available distance variable measures the Euclidian distance to the edge and not the centre of the greenspace. To make it compatible with the centre-to-centre distance used in estimating the marginal value function, a standardised distance from the edge to the centre of City-Edge Greenspace is added. ${ }^{14}$ The marginal value function used is hence the following

$$
\text { MValueEdge = MValue(Distance + 178.5, 10ha, Income, Population })
$$

Adjustments in both equation 2 and 3 make the derived values more conservative and robust as they are less sensitive to measurement error in the variables. This is especially relevant for Formal Recreation Sites where the distance variable used is somewhat inaccurate for small distances because it measures distance to the park centre rather than to its nearest edge, which is the ideal determinant of the benefits derived by households.

The distance decay functions illustrate the fact that, on average, people living closer to a park typically derive more benefits from its presence than those living further away. This can be attributed to several reasons. One is that the fraction of people using the site for recreational purposes decreases with distance (Bateman et al, 2006), another is that some of the non-

\footnotetext{
${ }^{14}$ Since the size of City-Edge Greenspace is standardised to 10ha (roughly the average size of Formal Recreation Sites in the studied sample), the distance added corresponds to the radius of a circle containing an area of 10ha, i.e. 178.5 metres.
} 
recreation ecosystem services such as noise abatement and pollution reduction tend to be greater the closer one lives to the site.

In section 4 the variation in benefits induced by a policy change is measured by integrating a marginal value function over the interval defined by that policy change.

\subsection{The Marginal Value Function for Informal Greenspace}

For the percentage of Informal Greenspace in a $1 \mathrm{~km}$ square, a marginal value function is derived based on results from Cheshire and Sheppard (1995) ${ }^{15}$. This takes the form:

$$
\text { MarginalVvalue }=0.02268 p^{2}-4.53686 p+226.843
$$

Where $p$ measures the percentage of Informal Greenspace cover in a $1 \mathrm{~km}^{2}$ square. The change in benefits caused by a policy affecting this percentage is computed by integrating the above function over the interval given by the current and some proposed alternative level of Informal Greenspace (e.g. the shaded area in Figure 2). The result is a monetary value for the change in discounted benefits induced by a change in the amount of Informal Greenspace in a household's vicinity.

Figure 2 illustrates Eq. 4. The marginal value decreases in the percentage of Informal Greenspace already available reflecting the standard saturation effect.

\section{[FIGURE 2]}

\section{Urban growth scenarios}

In order to apply the marginal value functions it is necessary to define the policy change to be evaluated. In this section we outline how the urban dimensions of the six NEA scenarios ${ }^{16}$ were translated into changes in the key urban variables included in the marginal value functions.

\footnotetext{
${ }^{15}$ Cheshire and Sheppard (1995) provide two estimates of mean marginal values: one for Reading (18\% of greenspace land coverage with a marginal value of $£ 120)$; and one for Darlington $(8 \%, £ 192)$ where the marginal values have been converted to 2009 prices. Additionally assumptions that the marginal value is zero at $100 \%$ and non-negative for smaller percentages of 'natural' land cover have been used to fit a quadratic function through those points.

${ }^{16}$ For a detailed description of the NEA scenarios see Haines-Young et al. (2011).
} 
The six NEA scenarios describe the UK in 2060 by specifying different changes in key urban parameters such as the area covered by settlements, the number of people living in such areas and the amount of urban greenspace. Table 3 presents the percentage changes between 2010 and 2060 for each of the scenarios.

\section{[TABLE 3]}

Considering Table 3, the World Market scenario has the most extreme impact on urban areas. Here, by 2060 the UK experiences dramatic urbanisation both in terms of urban extent and population resulting in an expansion of housing into green belt, parks and gardens results in a loss of greenspace. The National Security scenario also envisages a dramatic loss in formal recreation sites although this is now brought about by conversion into agricultural land. By contrast, other scenarios posit a fall in urban extent due to a variety of policies such as the reconversion of developed flood plains.

\subsection{Simulating urban growth in case study cities}

It is beyond the scope of this paper to explicitly and accurately simulate urban growth for our five city case studies. Instead the national level changes in urban growth parameters as used in the NEA are applied to the city level using operationally practical procedures as described below.

First, any changes in urban extent are represented by adjusting all distances to each Formal Recreation Site or City-Edge Greenspace. ${ }^{17}$ Second, the change in urban population is allowed for by increasing the number of individuals in each postcode by the scenario specified percentage. Similarly, Formal Recreation Sites are expanded or contracted in line with the specifications of each scenario ${ }^{18}$ as is the area of Informal Greenspace ${ }^{19}$. The effect

\footnotetext{
${ }^{17}$ Specifically we multiply the distances from the geographical centre of each postcodes to the centre of each Formal Recreation Site or City-Edge Greenspace by a factor equal to the square root of 1 plus the proportional change in the urban area (this being 0.98 for Nature@ Work, National Security and Local Stewardship, 1.015 for Go with the Flow and 1.338 for World Market; no change in extent is posited for the remaining scenarios).The square root is taken to translate a change in city area (see Table 3 ) into one in distance. The appropriateness of using a constant factor for all distances follows from the intercept theorem. This procedure effectively inflates or deflates a city preserving the set of postcodes included but adjusting their relative position.

${ }^{18}$ This presents a lower bound estimate for any given increase in Formal Recreation Site size. Adding a new park at a different location would generally generate higher benefits than adding the same area to an existing park. Note that the location of houses, are not changed over and above the inflation factor. The bias introduced by the artefact that some houses would be located within the new boundaries of a park is limited by the adjustment of the marginal value function described previously and illustrated in Figure 1.

${ }^{19}$ The Informal Greenspace cover is divided by $(1+$ the change in urban area) to allow for alteration in the size of the city.
} 
of income on the marginal value of urban greenspace is, as discussed in section 2.1 above, mainly driven by relative differences in income. Because scenarios do not specify changes in relative income, this is maintained within this analysis.

\subsection{Dynamic Aspects}

The NEA scenario descriptions specify the state of the world in 2060 but do not provide any details about intervening periods. This raises issues regarding the temporal distribution and discounting of benefits. Comparing a monetary value of the status quo with that of scenarioendpoints fifty years into the future is not straightforward since discounting the latter but not the former would obviously induce a substantial bias towards losses. Ideally any marginal change in ecosystem services provided would be valued at the point in time it occurs and discounted appropriately. However, this detailed information is not available.

To address this problem we use two approaches. Unless stated otherwise all values presented are undiscounted changes in ecosystem services. This is equivalent to assuming that any change in the provision of urban greenspace, population and city size implied by scenarios would occur instantaneously. ${ }^{20}$ This obviously results in an overestimation of any benefit change both at the household and at the country level. This can be easily corrected for by assuming that the changes in benefits are spread evenly across the fifty years considered. It is then sufficient to specify the discounting rule in order to compute an adjustment factor that transforms the values presented into the appropriate present values. ${ }^{21}$ Note that this adjustment only affects the per-household and aggregated values for the six scenarios but not the marginal value functions presented above. Final results are presented for both approaches.

An obvious candidate discounting rule is the one specified in the HM Treasury's Green Book (2003, Annex 6, Table 6.1) that discounts any net changes at 3.5\% for the first 30 years and at $3 \%$ for years 31 to 50 . The adjustment factor that transforms the undiscounted benefit changes into present values under this discounting regime is 0.47 . This is the discounting rule used for the country maps presented below and abbreviated 'H.M. Treasury uniform' in the tables.

\footnotetext{
${ }^{20}$ Note, the marginal value function represent discounted values in the sense that they give the present value of any change in benefits at the point in time they occur. The discounting that is the concern of this section is about taking into account that the point in time the change occurs might be in the future.

${ }^{21}$ This procedure assumes that for each individual value change computed (and as the next section describes there are millions of them included in this study) the marginal value function is constant and equal to the average marginal value. This procedure hence underestimates losses and overestimates gains because the real marginal value functions are downward sloping and changes occurring closer to the present are valued higher under any discounting regime.
} 
However, just applying the above discount rates introduces a degree of inconsistency. They are based on the assumption of a $2 \%$ average growth rate of the UK economy. However, four of the six NEA scenarios make different assumptions with growth rates in the range between 0.5\% (Local Stewardship scenario) and 3\% (Nature@Work). Using these growth rates instead of those used by the Treasury implies differentiated discount rates and hence adjustment factors for each scenario (starting at 0.395 for Nature@Work and rising up to 0.634 for the Local Stewardship case). This scenario specific discounting regime is labelled 'H.M. Treasury, scenario specific' in the tables below.

Another dynamic aspect is the growth of the urban population. Each NEA scenario specifies by how much the urban population will have increased by 2060 (see column three in Table 3). Hence, when aggregating per-household values into ones for Great Britain (see Section 5) it matters whether one uses the current size of the urban population or the projected, scenario specific one in 2060. In Section 5 the current population size is used. The values presented can be easily converted using the numbers presented in Table 4.

\section{Detailed Analysis for Five UK Cities}

Five UK cities, Aberdeen, Bristol, Norwich, Sheffield and Glasgow, are studied in detail with summary statistics for each being provided in Table 4. This selection embraces cities of varying size and location and therefore aids subsequent transferral of findings.

\section{[TABLE 4]}

For each city, a study area is defined as the developed land use area (OS Meridian DLUA) within the 2001 census District Area boundary for each city. Spatially referenced data on accessible greenspace is supplied by city councils, the UK Forestry Commission and Natural England. This data is used within a GIS to compute a layer of Formal Recreation Sites for each city. Euclidean distances from the centroid of each postcode to the centroid of each Formal Recreation Sites and to the border with City-Edge Greenspace were calculated for each city. ${ }^{22}$ Informal Greenspace was computed as defined above.

\footnotetext{
${ }^{22}$ A $3 \mathrm{~km}$ maximum distance was imposed for this and the City-Edge Greenspace calculations, reflecting an empirically based cut-off distance beyond which greenspace influence was assumed to be zero.
} 
For all postcodes, the number of households is obtained from the 2010 UK National Statistics Postcode Directory. ${ }^{23}$ Median gross annual household income for each postcode area was taken from the 2008 Experian Mosaic Public Sector data set at the Census Lower Super Output Area (LSOA).

The change in benefits derived from ecosystem services are simulated for each of the six scenarios. This is done by calculating the change in benefits brought about by the parameter changes given in Table 3 for Formal Recreation Sites, City-Edge Greenspace and Informal Greenspace for each full postcode in each of the cities. For City-Edge and Informal Greenspace between 4,248 (Norwich) and 12,548 (Glasgow) individual values are computed for each of the greenspace categories and scenarios. For the change in benefits derived from proximity to Formal Recreation Sites a much larger number of values are computed as the distance decay function Eq. 2 is applied to all relevant sites. As a result, between 45,800 (Norwich) and 360,000 (Glasgow) benefit changes are calculated per scenario. ${ }^{24}$

For each of the greenspace categories per-household values are multiplied with the number of households living in that particular area and then summed across all the postcodes of a city. These sums are then divided by the total number of households to yield the average perhousehold values presented in Table 5 for the case of Norwich. Note that the city boundary and hence the distance to City-Edge Greenspace does not change in the Green \& Pleasant Land Scenario and hence no value is reported in that category. All benefit changes reported here are undiscounted capital values.

\section{[TABLE 5]}

Table 6 presents mean per-household changes in total greenspace benefits for each scenario across all five cities. Here differences reflect the geography and distribution of present and future parks across the various cities. Three scenarios (Green \& Pleasant Land, Nature@ Work and Local Stewardship) result in an increase in urban ecosystem services with Nature@Work generating the highest benefits. The three other scenarios (World Market, National Security

\footnotetext{
${ }^{23}$ Full postcodes were used. A postcode area comprises on average about 20 households (excluding postcodes without residential addresses).

${ }^{24}$ For Formal Recreation Sites and City-Edge Greenspace the marginal value functions are integrated over the distance variable. The total value in the status quo and under each scenario is computed by taking the difference between the total value at $3 \mathrm{~km}$ and the respective distance. For each scenario the parameters for city population, distance and size are adjusted according to Table 6 . The undiscounted benefit change per household for each postcode and scenario is then given by the difference between the scenario and the status quo total values.
} 
and Go with the Flow) reduce the amount of urban ecosystem services provided in 2060 compared to their current level. Both World Market and National Security impose substantial ecosystem service losses on urban households with the former being significantly worse than the latter.

\section{[TABLE 6]}

\section{Extrapolation to Urban Areas in Great Britain}

Extrapolation to urban areas across Great Britain is achieved by first computing median perhousehold benefit changes at the LSOA (for English cities) or datazone (for Scottish cities) level. ${ }^{25}$ These values are modelled as a function of local characteristics such as total number of households, median gross household income in 2008, population density obtained at the LSOA/datazone level and the city's population. Table 7 presents OLS regressions for each scenario. $^{26}$

\section{[TABLE 7]}

Not surprisingly, the natural log of median income is highly significant ( $t$-values between 57 and 83) for all scenarios. The obvious reason being that it is one of the variables used to compute the values for Formal Recreation Sites and City-Edge Greenspace (see Eq. 2 and 3). In all regressions the coefficient of the income variable is very close to the coefficient used in the respective marginal value functions. Considering other variables, a city's population has a positive effect on the size of benefit changes although the coefficient of this variable is negative in the marginal value functions (Eq. 1 - Eq. 3). The variable CityPopulation hence picks up effects that are correlated with city size but cannot be explicitly controlled for in the above regressions, such as the number and size of parks and other greenspaces.

Population density is positively correlated with changes in urban ecosystem benefits for all but one scenario. City centres are typically the most densely populated area. They are hence also the ones that are both furthest away from non-urban greenspace and therefore rely most

\footnotetext{
${ }^{25}$ Our national extrapolation analysis is restricted to Great Britain as comparable data for Northern Ireland is not available. However, urban areas in Northern Ireland represent only about three percent of total urban area in the UK (Davies et al, 2011). Moreover, we have only included cities with a population of 50,000 or more as the methodology used is as less suitable for smaller settlements.

${ }^{26}$ They include only variables that could not be rejected as significant at the $1 \%$ level following a stepwise elimination procedure. The results for the full set of explanatory variables are given in Perino et al. (2011).
} 
heavily on urban ecosystem services. Formal Recreation Sites are often located near to city centres and hence a change in their size affects these households more than those living in a city's fringe. Davies et al. (2011) document an inverse relationship between population density and local greenspace provision. At the same time marginal benefits are typically higher the scarcer the good, resulting in a positive relationship between population density and changes in the benefits derived from urban ecosystem services. This establishes an alternative rationale for the relationship between population density and changes in benefits.

The number of households in a LSOA/datazone is also a highly significant predictor of values, exhibiting the expected positive sign. Interestingly, the city dummy for Glasgow is consistently negative while that for Norwich is positive suggesting some omitted factor affecting values. However, the goodness of fit is generally high. The regressions for Nature@Work and Go with the Flow suffer from heteroskedasticity and hence all $t$-values for those scenarios are computed using robust standard errors.

\subsection{Extrapolation and aggregation at national level.}

The coefficients presented in Table 7 are used to extrapolate the per-household changes in benefits derived from urban ecosystem services for all LSOA/datazones in Great Britain that are part of a city with a population of 50,000 or more for each scenario. ${ }^{27}$ The reasons for this restriction are twofold. First, the importance of urban greenspace naturally decreases rapidly for towns smaller than this threshold due to the increased proximity to the non-urban land surrounding the town. Second, the smallest urban area studied in detail is Norwich with a population of about 180,000 . Extrapolating the values generated to settlements smaller than 50,000 would not seem very plausible. The cities included in the extrapolation cover more than 25,000 LSOA/datazones and nearly 40 million people or about two thirds of the population in Great Britain. ${ }^{28}$

Table 8 presents average changes in benefits for urban households in Great Britain and the aggregate value of these changes for entire Great Britain both undiscounted and using both discount regimes presented above for the period 2010-2060. While these numbers should be viewed as rough estimates only, they make clear that the impacts of the scenarios and hence

\footnotetext{
${ }^{27}$ The areas of LSOA for Wales are not available and have been replaced by the median size of LSOAs/datazones in England and Scotland $\left(329616.9 \mathrm{~m}^{2}\right)$.

${ }^{28}$ The cities for England and Wales are selected using 2001 census data (DCLG, 2008) and for Scotland using mid-2008 population estimates (GROS, 2008). LSOAs and datazones are then selected based on look-up tables by EDINA UKBORDERS that match city codes to output areas. Median household income is extracted from the 2008, Experian Mosaic data set. Note that the most extreme $0.5 \%$ of LSOAs were truncated to the value at that truncation point to avoid extreme values distorting mean results.
} 
future policy decisions can have substantial impacts on the value of ecosystem services provided in urban areas. In the very extreme case of the World Market scenario the discounted losses amount to roughly half of the UK's GDP in 2009.

Table 8 also reveals the effects of moving from the H.M. Treasury's uniform discounting rule to one that takes into account the different growth rates in the respective scenarios and hence is scenario specific. Note that for Green \& Pleasant Land and World Market the growth rate is equal to the $2 \%$ assumed by H.M. Treasury (2003) and hence there is no difference between the two discounting regimes. For Nature@Work the net present value is reduced by about 16\%. For National Security, Local Stewardship and the Go with the Flow scenarios the absolute value of the benefit change increases by up to a third as their growth rates are below the one used by the H.M. Treasury

\section{[TABLE 8]}

Although the absolute value of gains between the beneficial Green \& Pleasant Land, Nature@Work and Local Stewardship scenarios is substantial, their relative spatial distribution is similar. Therefore we can display all three of these in Figure 3 and only differentiate them via the different keys given under this figure. A similar approach is adopted for the mapping of losses shown in Figure 4 for the World Market, National Security and Go with the Flow scenarios. Considering both of these figures we see that the largest values (whether positive or negative) are, not surprisingly, concentrated within the biggest cities; a finding which supports our empirical decision to exclude small towns from this analysis.

[FIGURES 3 AND 4]

\subsection{Distributional weights}

We follow H.M. Treasury (2003, Annex 5) recommendations for aggregating benefits and apply distributional weights to our analysis in order to correct for the fact that the marginal utility of consumption is unlikely to be equal across all individuals. The distributional weight for each LSOA is calculated by dividing the median UK household income by the median household income in the LSOA. The median income of households on the UK is assessed using the same data source as above (Experian Mosaic, 2008) which details both median gross household incomes and the number of household for all LSOAs. By ordering all LSOAs 
with respect to income and computing the cumulative number of households allowed us to obtain the median urban household income for the UK in 2008, which was £25,275.

Comparing Table 8 with Table 9 illustrates the impact of distributional weights on the net present value per urban household of each scenario. The benefit changes increase by up to about thirty percent if distributional weights are applied. This indicates that any reduction (increase) in the amount of urban greenspace would disproportionally hurt (benefit) the poor.

\section{[TABLE 9]}

\section{Conclusion}

Urban greenspace, while under constant pressure due to the demand for housing and commercial development, generates substantial benefits to local communities. This paper has attempted to quantify these benefits at a national scale. Combining benefit transfer methods and detailed GIS data on a number of UK cities, per household changes in benefits are identified and extrapolated for England, Wales and Scotland for the six NEA scenarios. This analysis shows that changes in the provision of urban greenspace can create, or destroy, billions of pounds worth of benefits to local residents.

The analysis also presents a methodology for estimating the spatial distribution of gains and losses arising from well specified policy changes. It therefore provides an important tool for the analysis of policies varying the amount, location and accessibility of urban greenspace.

We conclude by acknowledging some of the caveats of our analysis.

First, a number of the benefits people derive from urban ecosystem services could not or only partially be considered in our analysis. For example the benefit of living in a 'green' city as opposed to living near to a park (Formal Recreation Site) or in a 'green' neighbourhood (Informal Greenspace) cannot be captured by the methods applied in this paper. This limitation is likely to result in an underestimation of the true marginal value of urban ecosystem services. 
Secondly, the value functions used are only as good as the original studies they are based upon. While those studies have been chosen to meet certain standards, they still differ in quality and are limited in scope.

Thirdly, there is a fundamental problem in that the methods employed by those original studies do not allow us to separate the different categories of value generated by urban greenspaces. This becomes an issue when transferring values from the original study site to other sites as the composition of services might differ between the two. Although the set of original studies comprises a quite representative sample of UK urban green spaces, the inability to condition on greenspace characteristics (apart from size) remains a potentially serious drawback. More extensive, sophisticated and standardised original studies (such as those conducted for different goods by Kirchhoff et al., 1997; Bergstrom and Taylor, 2006; Troy and Wilson, 2006; Eigenbrod et al., 2010) could potentially provide enough detail to allow for such a disaggregation of benefit categories.

Fourthly, as discussed in Davies et al. (2011), standardised data indicating quality or other features of urban greenspaces is not generally available. Combined with more refined valuation results, such additional detail of the GIS data would greatly enhance the reliability of the benefit transfer method.

Last but not least, some of the scenarios (e.g. World Market) imply radical changes in urban extent, population and greenspace provision. The ability to credibly model the impacts of such major increases in urbanisation based upon existing data is clearly an open empirical question. Consequently, values for such extreme scenarios should be treated with caution and taken as indicative only.

Addressing these caveats would clearly form a substantial agenda for future research. 


\section{References}

Andrews, Barnaby (2009) An investigation into the effects of distance and environmental attitudes on preferences for new parks in Norwich, unpublished MRes dissertation, University of East Anglia, Norwich

Bateman, I.J., Day, B.H., Georgiou, S. and Lake, I. (2006) The aggregation of environmental benefit values: Welfare measures, distance decay and total WTP, Ecological Economics, 60(2): 450-460. DOI: 10.1016/j.ecolecon.2006.04.003

Bateman, I.J., Jones, A.P., Lovett, A.A., Lake, I. and Day B.H. (2002) Applying geographical information systems (GIS) to environmental and resource economics, Environmental and Resource Economics, 22(1-2): 219-269. DOI: 10.1023/A:1015575214292

Bergstrom, John C. And Laura O. Taylor (2006) Using meta-analysis for benefit transfer: Theory and practice, Ecological Economics 60, 351-360.

Brander, L. M. and Koetse, M. J. (2011) The value of urban open space: Meta-analyses of contingent valuation and hedonic pricing results, Journal of Environmental Management 92, 2763-2773.

CabeSpace (2005) Does money grow on trees? CABE, London, 87pages

Cheshire, Paul and Stephen Sheppard (1995) On the price of land and the value of amenities, Economica 62, 247-67

Davies, L., Kwiatkowski, L., Gaston, K. J., Beck, H., Brett, H., Batty, M., Scholes, L., Wade, R., Sheate, W. R., Sadler, J., Perino, G., Andrews, B., Kontoleon, A., Bateman, I., Harris, J. A., Burgess, P., Cooper, N., Evans, S., Lyme, S., McKay, H. I., Metcalfe, R., Roger, K., Simpson, L. and Winn, J. (2011), Urban, UK National Ecosystem Assessment, Chapter 10

DCLG (2008) Urban Settlement 2001: England and Wales, Department of Communities and Local Government, http://www.communities.gov.uk/publications/planningandbuilding/urbansettlement2001 (accessed: 14/11/2010)

Dehring, Carolyn and Neil Dunse (2006) Housing density and the effect of proximity to public open space in Aberdeen, Scotland, Real Estate Economics 34(4), 553-566

Dunse, Neil, Michael White and Carolyn Dehring (2007) Urban parks, open space and residential property values, RICS Research paper series 7(8) 40 pages

Eigenbrod, Felix, Paul R. Armsworth, Barbara J. Anderson, Andreas Heinemeyer, Simon Gillings, David B. Roy, Chris D. Thomas and Kevin J. Gaston (2010) Error propagation associated with benefit transfer-based mapping of ecosystem services, Biological Conservation, forthcoming 
Experian, Mosaic UK 2009/2008 [Shapefile geospatial data]

http://www.experian.co.uk/business-strategies/mosaic-uk-2009.html Accessed August, 2010

Forestry Commission, Woodland Trust and the Environment and Heritage Service (Northern Ireland) Woods For People - Version 4, Coverage: GB, Updated November 2007. From Forestry Commission CGIS, Victoria Terrace, Aberystwyth.

General Register Office for Scotland, 2001 Census: Digitised Boundary Data (Scotland) [computer file]. ESRC/JISC Census Programme, Census Geography Data Unit (UKBORDERS), EDINA (University of Edinburgh).

GROS (2008) Table 2: Mid-2008 Population Estimates - Localities in order of size, General Register Office for Scotland, http://www.gro-scotland.gov.uk/files2/stats/populationestimates/08mye-localities-table2.pdf (accessed 14/11/2010)

Haines-Young, R.; Paterson, J.; Potschin, M.; Wilson, A. and Kass, G. (2011): The UK NEA Scenarios: Development of storylines and analysis of outcomes, The UK National Ecosystem Assessment, chapter 25.

Hanley, Nick and Jacqui Knight (1992) Valuing the environment: recent UK experience and an application to Green Belt Land, Journal of Environmental Planning and Management 35(2), 145-160

HM Treasury (2003) The Green Book: Appraisal and Evaluation in Central Government, London

Kirchhoff, Stefanie, Bonnie G. Colby and Jeffrey T. LaFrance (1997) Evaluating the Performance of Benefit Transfer: An Empirical Inquiry, Journal of Environmental Economics and Management 33, 75-93.

Natural England, CRoW Act 2000 - Access Layer [ESRI Shape file]. http://www.gis.naturalengland.org.uk/pubs/gis/GIS_register.asp Accessed: August 2010 Natural England, CRoW Act 2000 - S16 Dedicated Land [ESRI Shape file]. http://www.gis.naturalengland.org.uk/pubs/gis/GIS_register.asp Accessed: August 2010 Natural England, CRoW Act 2000 - S15 Land [ESRI Shape file]. http://www.gis.naturalengland.org.uk/pubs/gis/GIS_register.asp Accessed: August 2010 Office for National Statistics, National Statistics Postcode Directory (NSPD) 2010 February Version [computer file]. ESRC Census Programme, Census Dissemination Unit, Mimas (University of Manchester)/Census Geography Data Unit (UKBORDERS), EDINA (University of Edinburgh) 
Office for National Statistics, 2001 Census: Digitised Boundary Data (England and Wales) [computer file]. ESRC/JISC Census Programme, Census Geography Data Unit (UKBORDERS)

OS MasterMap Topography Layer [GML geospatial data], Coverage: Aberdeen, Bristol, Norwich, Glasgow and Sheffield, Updated June 2010, Ordnance Survey, GB. Using: EDINA Digimap Ordnance Survey Service, <http://edina.ac.uk/digimap>, Downloaded: August 2010

OS Meridian 2 (DLUA) [Shapefile geospatial data], Scale 1:50,000, Coverage: UK, Updated April 2010, Ordnance Survey, GB. Using EDINA Digimap Ordnance Survey Service, <http://edina.ac.uk/digimap>, Downloaded: August 2010

OS Code Point with Polygons [Shapefile geospatial data], Coverage: Aberdeen, Bristol, Norwich, Glasgow and Sheffield, Updated March 2010, Ordnance Survey, GB. Using: EDINA Digimap Ordnance Survey Service, <http://edina.ac.uk/digimap>, Downloaded: August 2010

Perino, G., Andrews, B., Kontoleon, A. and Bateman, I. (2011) Urban Greenspace Amenity, Economic Assessment of Ecosystem Services provided by UK Urban Habitats, Report to the Economics Team of the UK National Ecosystem Assessment, University of East Anglia, http://uknea.unepwcmc.org/LinkClick.aspx ?fileticket=80gPu556Qhw\%3d\&tabid=82 (accessed: 09 December 2011)

Troy, Austin and Matthew A. Wilson (2006) Mapping ecosystem services: Practical challenges and opportunities in linking GIS and value transfer, Ecological Economics 60, 435-449 


\section{Appendix:}

Table A.1.Description of variables used in meta-analysis

\begin{tabular}{|l|l|}
\hline \multicolumn{1}{|c|}{ Variable } & \multicolumn{1}{|c|}{ Description } \\
\hline $\begin{array}{l}\text { Marginal value of proximity } \\
\text { to FRS (£ in } 2009 \text { prices per } \\
\text { meter) }\end{array}$ & $\begin{array}{l}\text { Marginal value of proximity elicited for the greenspace, i.e. the } \\
\text { additional value of moving one meter closer to the Formal } \\
\text { Recreation Site. For hedonic pricing method those are implicit } \\
\text { prices, for the expert method it is the experts' estimate of the } \\
\text { implicit price and for the contingent valuation studies it is either } \\
\text { willingness-to-pay for the creation of a new park or willingness- } \\
\text { to-pay to preserve an existing one. }\end{array}$ \\
\hline Size of greenspace (in ha) & Size of the greenspace valued in original study. \\
\hline Distance (in m) & $\begin{array}{l}\text { Distance between the greenspace valued and the place of } \\
\text { residence of the person/household carrying this value. }\end{array}$ \\
\hline Income (GBP) & $\begin{array}{l}\text { Income of the study area based on averages over median annual } \\
\text { household incomes at the Lower Super Output Areas of the 2001 } \\
\text { census (using the 2009, Experian Mosaic data set). }\end{array}$ \\
\hline Population & $\begin{array}{l}\text { Population of the city where the original study was undertaken } \\
\text { (using 2009 ONS estimates). }\end{array}$ \\
\hline CVM & $\begin{array}{l}\text { Dummy variable: 1if original study uses the contingent valuation } \\
\text { method, 0 otherwise. }\end{array}$ \\
\hline Expert Method & $\begin{array}{l}\text { Dummy variable: 1if original study uses the expert method, 0 } \\
\text { otherwise. }\end{array}$ \\
\hline Hedonic & $\begin{array}{l}\text { Dummy variable: 1if original study uses the hedonic pricing } \\
\text { method, 0 otherwise. Not reported as each original study used } \\
\text { only one of the three methods. }\end{array}$ \\
\hline Peer Reviewed & $\begin{array}{l}\text { Dummy variable: 1if original study was published in a peer- } \\
\text { reviewed journal, 0 otherwise. }\end{array}$ \\
\hline Year of Data Collection & Year the data of the original study was collected. \\
\hline
\end{tabular}




\section{FIGURES}

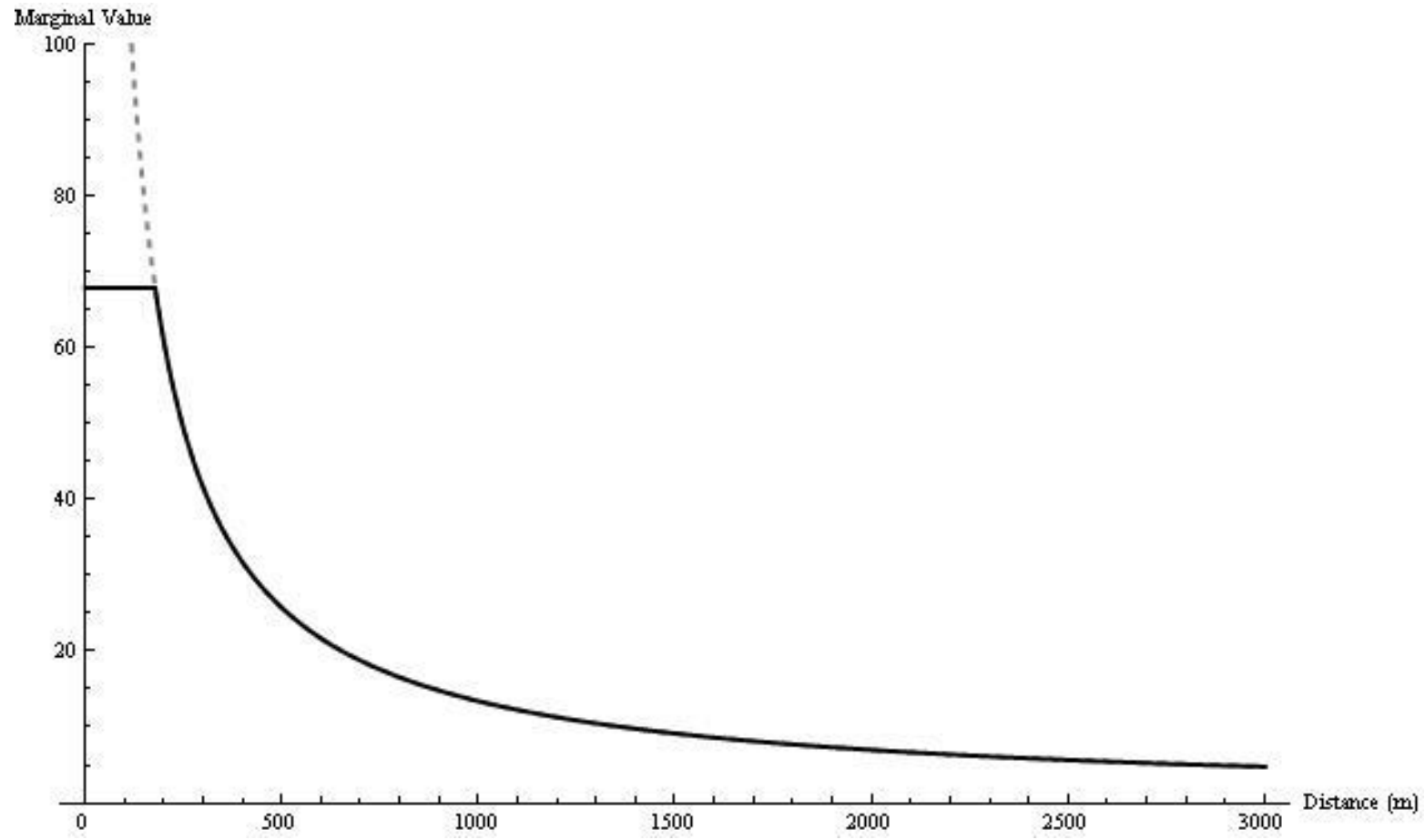

Figure 1: Distance decay function of marginal values for Formal Recreation Sites for a 10 ha park, population of 200,000 and income of 25,000)

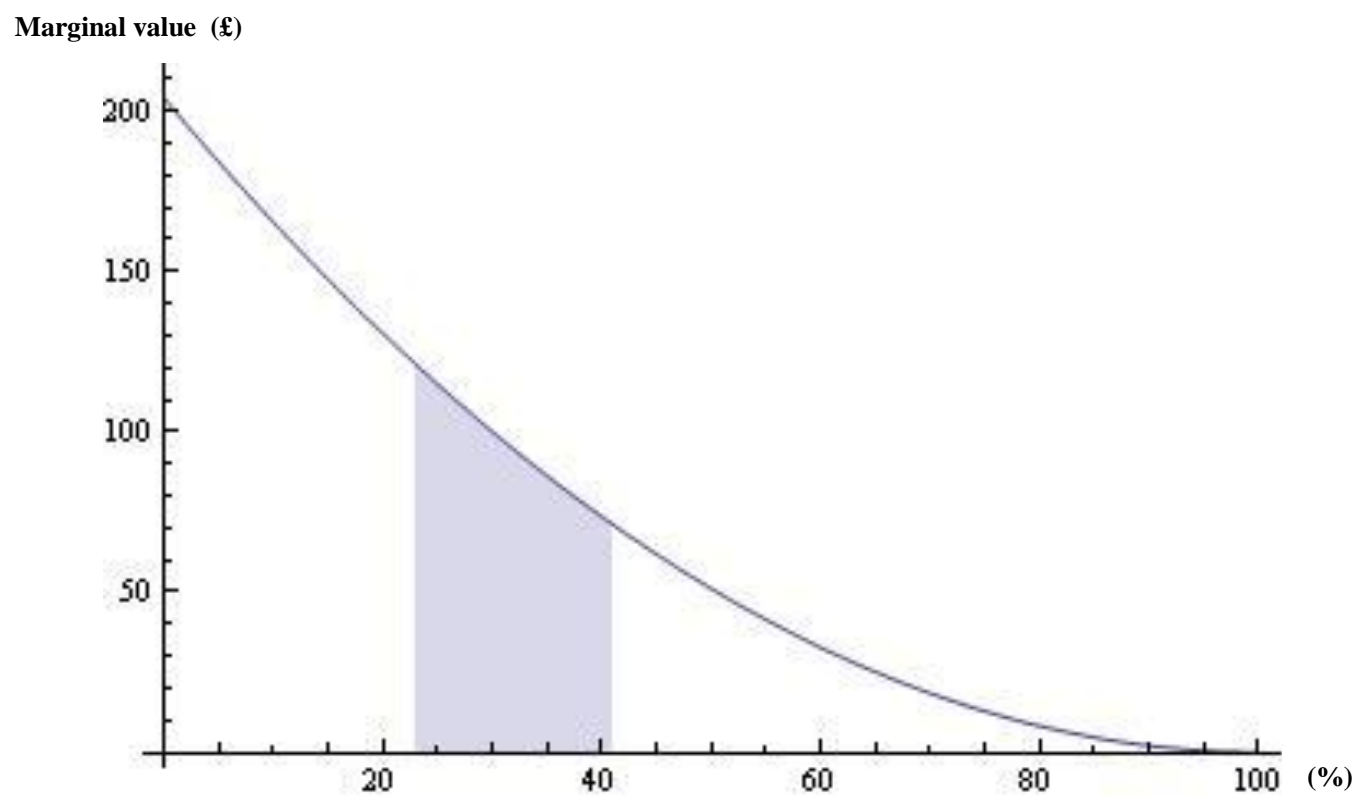

Figure 2: Marginal value of $\%$ of Informal Greenspace in a $1 \mathrm{~km}^{2}$ square 


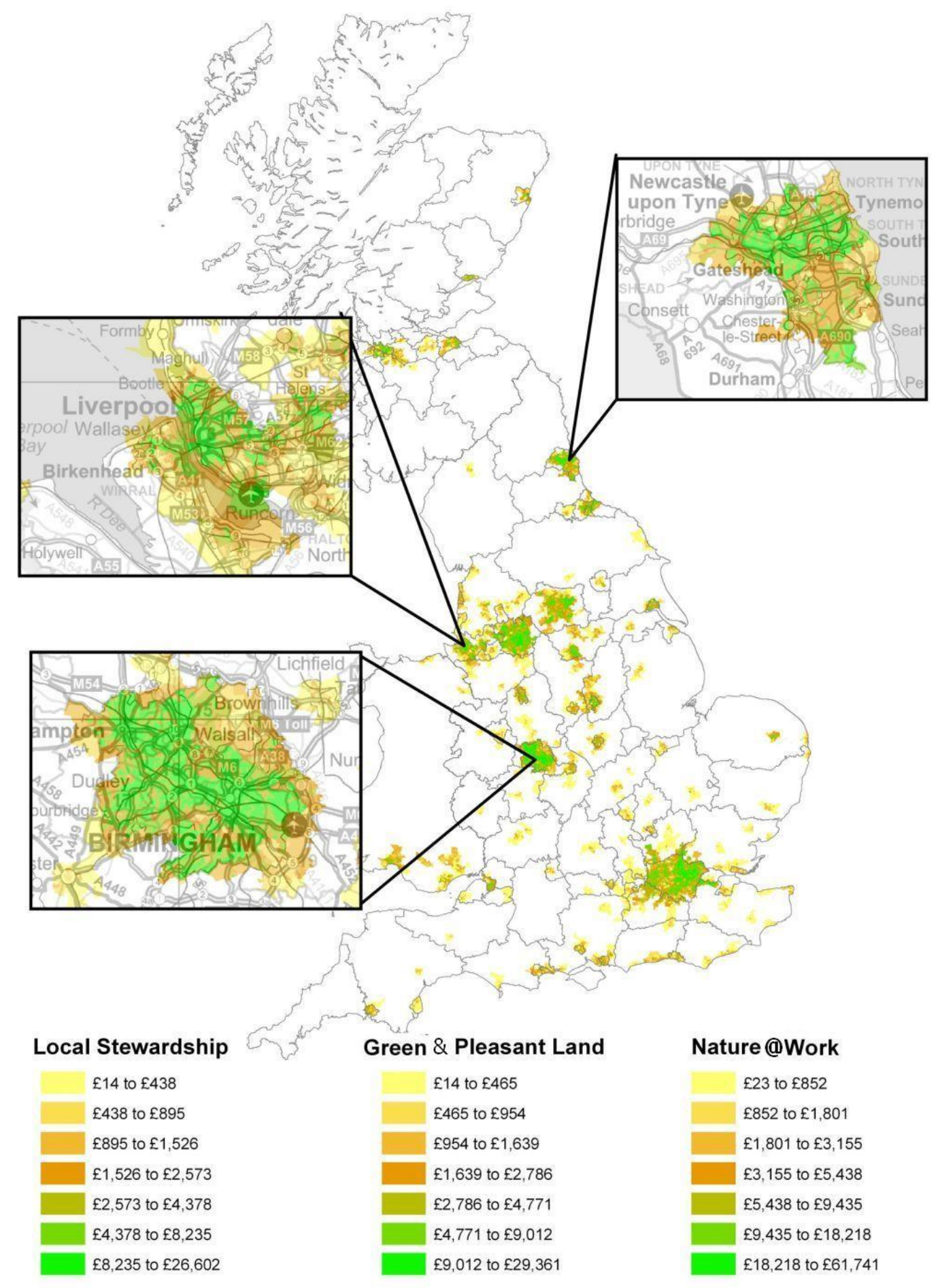

Figure 3: Spatial distribution of benefit changes under the scenarios which yield net gains for all cities with a population of 50,000 or more in Great Britain (net present value using HM Treasury (2003) standard discount rates) 


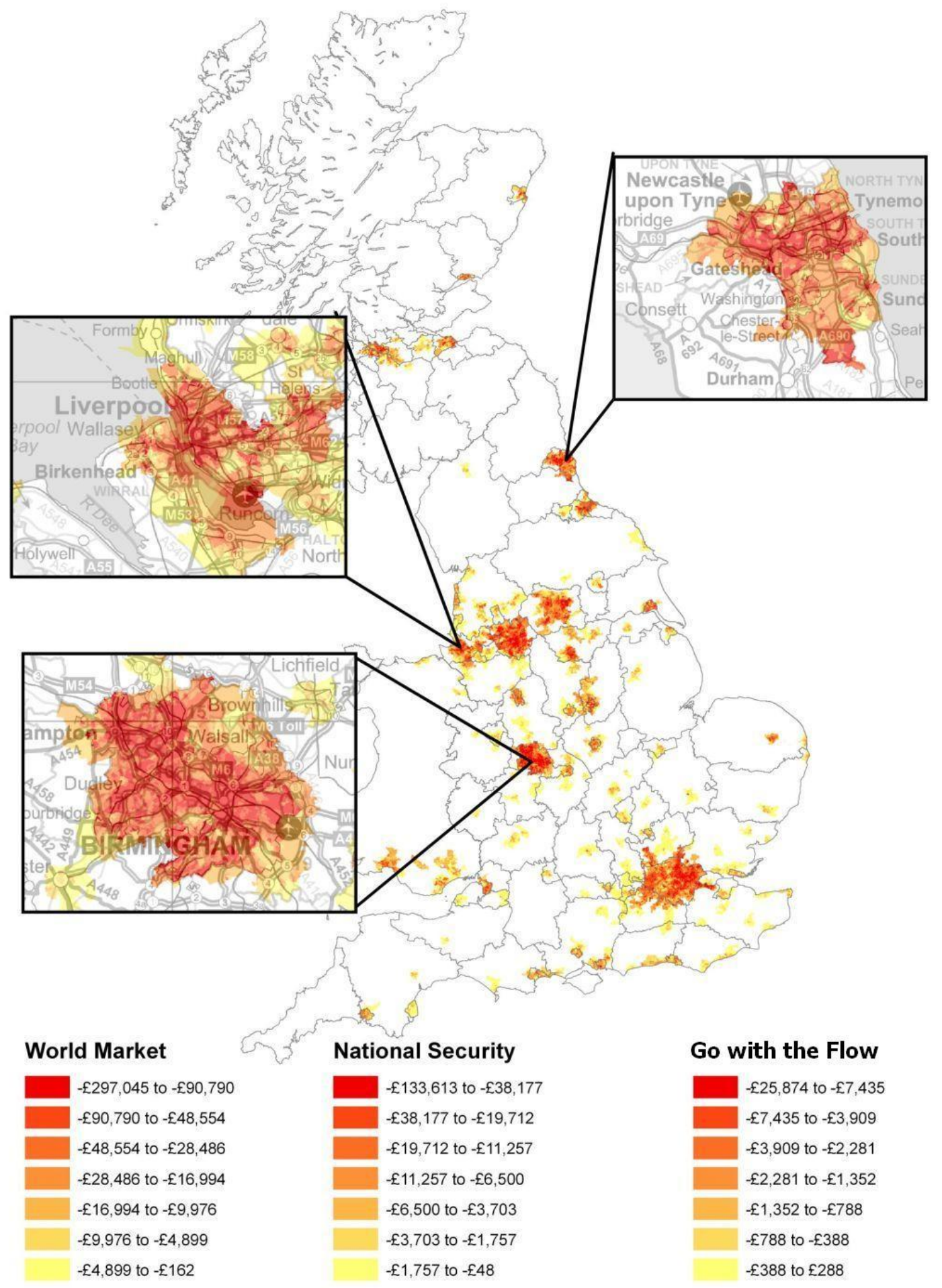

Figure 4: Spatial distribution of benefit changes under the scenarios which yield net losses for all cities with a population of 50,000 or more in Great Britain (net present value using HM Treasury (2003) standard discount rates) 


\section{TABLES}

Table 1: Summary statistic of meta-analysis dataset used to derive the marginal value functions for Formal Recreation Sites and City-Edge Greenspace.

\begin{tabular}{|c|c|c|c|c|c|c|}
\hline Variable & Description & Mean & Median & Std. Dev. & Min & Max \\
\hline MValue & $\begin{array}{l}\text { Marginal value of } \\
\text { proximity to } \\
\text { Formal Recreation } \\
\text { Site ( } £ \text { in } 2009 \\
\text { prices per meter) }\end{array}$ & 150.2 & 5.3 & 473.2 & -40.7 & $3,347.6$ \\
\hline Size & $\begin{array}{l}\text { Size of greenspace } \\
\text { (in ha) }\end{array}$ & 34.5 & 18 & 50.5 & 0.5 & 180 \\
\hline Distance & $\begin{array}{l}\text { Distance (in m) } \\
\text { from greenspace } \\
\text { centre to point of } \\
\text { elicitation. }\end{array}$ & 406.1 & 300 & 281.0 & 35 & 1,500 \\
\hline Income & $\begin{array}{l}\text { Household income } \\
\text { (£/year) }\end{array}$ & 39,153 & 29,413 & 8,119 & 16,071 & 48,015 \\
\hline Population & $\begin{array}{l}\text { Population of study } \\
\text { area }\end{array}$ & 471,141 & 213,800 & $1,357,238$ & 4,505 & $7,753,600$ \\
\hline No.Obs. & $\begin{array}{l}\text { No. Obs. in } \\
\text { original study }\end{array}$ & 4,353 & 166 & 10,292 & 3 & 32,539 \\
\hline \multirow[t]{2}{*}{$\begin{array}{l}\text { PeerReview } \\
\text { ed }\end{array}$} & $\begin{array}{l}\text { Peer Reviewed } \\
(1=\text { yes })\end{array}$ & .525 & 1 & .506 & 0 & 1 \\
\hline & $\begin{array}{l}\text { Year of Data } \\
\text { Collection }\end{array}$ & 1992 & 1984 & 10.1 & 1984 & 2009 \\
\hline
\end{tabular}

Note: A full description of variables is given in the appendix. 
Table 2: Meta-analysis regression result for Formal Recreation Sites and City-Edge Greenspace using a two stage Heckman procedure.

\begin{tabular}{lc}
\multicolumn{1}{c}{ lnMValue+ } \\
\hline \multicolumn{1}{c}{ Valuation } & equation \\
lnDistance & $-0.941^{* * *}$ \\
& $(0.008)$ \\
lnSize & $0.500^{* *}$ \\
& $(0.032)$ \\
lnIncome & $-2.945^{* *}$ \\
& $(0.011)$ \\
lnPopulation & $-0.554^{* *}$ \\
& $(0.021)$ \\
Constant & $44.53^{* * *}$ \\
& $(0.001)$ \\
\hline \multirow{2}{*}{ Selection equation } \\
lnIncome & $-1.196^{*}$ \\
& $(0.068)$ \\
Expert & $2.685^{*}$ \\
& $(0.051)$ \\
No.Obs & $0.000132^{* *}$ \\
& $(0.016)$ \\
PeerReviewed & 1.916 \\
& $(0.144)$ \\
Constant & 10.27 \\
& $(0.131)$ \\
\hline Mills lambda & 1.258 \\
& $(0.137)$ \\
\hline Observations & 61 \\
&
\end{tabular}

$p$-values in parentheses; ${ }^{*} p<0.10, * * p<0.05, * * * p<0.01$ 
Table 3: Changes in key urban parameters implied by NEA scenarios 2010-2060.

\begin{tabular}{lcccc}
\hline Scenario & $\begin{array}{c}\text { Change in } \\
\text { Urban Area } \\
\text { in \% }\end{array}$ & $\begin{array}{c}\text { Change in Urban } \\
\text { Population in \% }\end{array}$ & $\begin{array}{c}\text { Change of } \\
\text { FRS Area in } \\
\%\end{array}$ & $\begin{array}{c}\text { Change of Informal } \\
\text { Greenspace Area in } \\
\%\end{array}$ \\
\hline Green \& Pleasant Land & 0.0 & 21.7 & 38.9 & 5.4 \\
Nature @ Work & -3.0 & 13.8 & 39.0 & -4.9 \\
World Market & 79.0 & 52.6 & 73.0 & 20.7 \\
National Security & -3.0 & 17.2 & -34.3 & 4.8 \\
Local Stewardship & -3.0 & 0.0 & 4.5 & 2.8 \\
Go with the Flow & 3.0 & 32.2 & 36.2 & 0.0 \\
\hline
\end{tabular}

Source: NEA Scenario team

Table 4: Characteristic variables of cities included in the study area. ${ }^{1}$

\begin{tabular}{|c|c|c|c|c|c|}
\hline & Aberdeen & Bristol & Glasgow & Norwich & Sheffield \\
\hline Population in study area ${ }^{2}$ & 210,400 & 402,358 & 588,470 & 181,340 & 473,746 \\
\hline Households in study area ${ }^{3}$ & 91,616 & 169,080 & 272,847 & 84,576 & 204,025 \\
\hline $\begin{array}{l}\text { Number of formal recreation } \\
\text { sites }(>1 \text { ha) }\end{array}$ & 77 & 67 & 223 & 33 & 134 \\
\hline $\begin{array}{l}\text { Total area of formal } \\
\text { recreation sites (ha) }\end{array}$ & 738 & 1,318 & 2,225 & 401 & 1,772 \\
\hline $\begin{array}{l}\text { Area of Formal Recreation } \\
\text { Sites per household }\left(\mathrm{m}^{2}\right)\end{array}$ & 80.5 & 77.9 & 81.6 & 47.4 & 86.8 \\
\hline Informal Greenspace (ha) & 1,443 & 2,174 & 6,026 & 3,531 & 2,866 \\
\hline $\begin{array}{l}\text { Informal Greenspace per } \\
\text { household }\left(\mathrm{m}^{2}\right)\end{array}$ & 157.5 & 128.6 & 220.9 & 417.5 & 140.5 \\
\hline
\end{tabular}


Table 5: Per household benefit changes as for all greenspace categories and scenarios for Norwich 2010-2060 (undiscounted).

\begin{tabular}{lcccc}
\hline & $\begin{array}{c}\text { Formal } \\
\text { Recreation Sites }\end{array}$ & $\begin{array}{c}\text { City-Edge } \\
\text { Greenspace }\end{array}$ & $\begin{array}{c}\text { Informal } \\
\text { Greenspace }\end{array}$ & Sum \\
\hline Green \& Pleasant Land & $£ 7,970$ & n.a. & $£ 389$ & $£ 8,358$ \\
Nature@ Work & $£ 18,000$ & $£-2,020$ & $£ 258$ & $£ 16,238$ \\
World Market & $£-71,900$ & $£-10,800$ & $£-780$ & $£-83,480$ \\
National Security & $£-33,900$ & $£-2,520$ & $£ 195$ & $£-36,225$ \\
Local Stewardship & $£ 7,070$ & $£ 249$ & $£ 305$ & $£ 7,624$ \\
Go with the Flow & $£-3,980$ & $£-4,880$ & $£ 192$ & $£-8,668$ \\
\hline
\end{tabular}

Table 6: Benefit changes per household for all cities in the study area and scenarios aggregated over greenspace categories 2010-2060 (undiscounted)

\begin{tabular}{lccccc}
\hline & Aberdeen & Bristol & Glasgow & Norwich & Sheffield \\
\hline Green \& Pleasant Land & $£ 7,992$ & $£ 6,614$ & $£ 1,078$ & $£ 8,358$ & $£ 11,315$ \\
Nature @Work & $£ 16,377$ & $£ 13,781$ & $£ 1,750$ & $£ 16,238$ & $£ 24,229$ \\
World Market & $£-83,695$ & $£-69,587$ & $£-14,753$ & $£-83,480$ & $£-110,877$ \\
National Security & $£-34,584$ & $£-28,252$ & $£-4,228$ & $£-36,225$ & $£-47,667$ \\
Local Stewardship & $£ 7,442$ & $£ 6,290$ & $£ 1,182$ & $£ 7,624$ & $£ 10,372$ \\
Go with the Flow & $£-7,623$ & $£-5,957$ & $£-1,835$ & $£-8,668$ & $£-8,089$ \\
\hline
\end{tabular}


Table 7: GB Regression of median per household benefit changes at LSOA/Datazone level for all scenarios used to specify the extrapolation functions. Dependent variable: Welfare change per household at LSOA-level.

\begin{tabular}{|c|c|c|c|c|c|c|}
\hline & Green \& Pleasant Land & Nature@Work & World Market & National Security & Local Stewardship & Go with the Flow \\
\hline & $\begin{array}{c}(1) \\
\operatorname{lnGaP}\end{array}$ & $\begin{array}{c}(2) \\
\operatorname{lnNaW}\end{array}$ & $\begin{array}{c}(3) \\
\operatorname{Ln}(-\mathrm{WM})\end{array}$ & $\begin{array}{c}(4) \\
\operatorname{Ln}(-\mathrm{NS})\end{array}$ & $\begin{array}{c}(5) \\
\operatorname{lnLS}\end{array}$ & $\begin{array}{c}(6) \\
\operatorname{Ln}(-\mathrm{BAU})\end{array}$ \\
\hline lnCityPopulation & $\begin{array}{l}0.704 * * * \\
(15.00)\end{array}$ & $\begin{array}{l}0.709 * * * \\
(10.97)\end{array}$ & $\begin{array}{c}0.688 * * * \\
(16.69)\end{array}$ & $\begin{array}{c}0.728 * * * \\
(15.99)\end{array}$ & $\begin{array}{l}0.692 * * * \\
(16.15)\end{array}$ & $\begin{array}{c}0.706^{* * *} \\
(15.35)\end{array}$ \\
\hline $\operatorname{lnLSOA-HH}$ & $\begin{array}{c}0.240 * * * \\
(5.14)\end{array}$ & $\begin{array}{c}0.295^{* * *} \\
(4.29)\end{array}$ & $\begin{array}{l}0.316^{* * *} \\
(7.69)\end{array}$ & $\begin{array}{l}0.250 * * * \\
(5.52)\end{array}$ & $\begin{array}{l}0.286 * * * \\
\quad(6.70)\end{array}$ & $\begin{array}{c}0.263 * * * \\
(4.12)\end{array}$ \\
\hline lnLSOA-Income & $\begin{array}{c}-3.000 * * * \\
(-72.44)\end{array}$ & $\begin{array}{l}-3.131 * * * \\
(-74.85)\end{array}$ & $\begin{array}{l}-3.020 * * * \\
(-82.96)\end{array}$ & $\begin{array}{c}-3.212 * * * \\
(-79.91)\end{array}$ & $\begin{array}{l}-2.988 * * * \\
(-78.92)\end{array}$ & $\begin{array}{c}-3.225 * * * \\
(-57.51)\end{array}$ \\
\hline lnLSOA-Pop-Density & $\begin{array}{c}0.108 * * * \\
(7.32)\end{array}$ & $\begin{array}{c}0.136 * * * \\
(7.05)\end{array}$ & $\begin{array}{l}0.0969 * * * \\
\quad(7.49)\end{array}$ & $\begin{array}{l}0.0846 * * * \\
\quad(5.93)\end{array}$ & $\begin{array}{c}0.113 * * * \\
(8.39)\end{array}$ & \\
\hline Glasgow & $\begin{array}{c}-0.865 * * * \\
(-16.96)\end{array}$ & $\begin{array}{c}-0.810 * * * \\
(-12.04)\end{array}$ & $\begin{array}{c}-0.906 * * * \\
(-20.25)\end{array}$ & $\begin{array}{c}-0.944 * * * \\
(-19.10)\end{array}$ & $\begin{array}{c}-0.855 * * * \\
(-18.38)\end{array}$ & $\begin{array}{c}-1.253 * * * \\
(-27.09)\end{array}$ \\
\hline Norwich & $\begin{array}{c}0.933 * * * \\
(15.00)\end{array}$ & $\begin{array}{c}0.830 * * * \\
(10.58)\end{array}$ & $\begin{array}{c}0.889 * * * \\
(16.22)\end{array}$ & $\begin{array}{c}0.998 * * * \\
(16.50)\end{array}$ & $\begin{array}{c}0.899 * * * \\
(15.78)\end{array}$ & $\begin{array}{c}1.145^{* * *} \\
(19.97)\end{array}$ \\
\hline Sheffield & $\begin{array}{c}0.140 * \\
(3.11)\end{array}$ & $\begin{array}{c}0.179 * * \\
(3.87)\end{array}$ & $\begin{array}{c}0.112 * \\
(2.85)\end{array}$ & $\begin{array}{c}0.146 * * \\
(3.35)\end{array}$ & $\begin{array}{c}0.132 * \\
(3.22)\end{array}$ & \\
\hline Constant & $\begin{array}{c}28.36 * * * \\
(50.93)\end{array}$ & $\begin{array}{c}30.08 * * * \\
(42.70)\end{array}$ & $\begin{array}{c}30.57 * * * \\
(62.53)\end{array}$ & $\begin{array}{c}31.38 * * * \\
(58.13)\end{array}$ & $\begin{array}{c}28.06 * * * \\
(55.19)\end{array}$ & $\begin{array}{c}29.69 * * * \\
(44.07)\end{array}$ \\
\hline $\begin{array}{l}\text { Observations } \\
\text { Adjusted } R^{2} \\
\text { df_r } \\
\text { F }\end{array}$ & $\begin{array}{c}1635 \\
0.782 \\
1627 \\
836.5\end{array}$ & $\begin{array}{c}1636 \\
0.778 \\
1628 \\
917.8\end{array}$ & $\begin{array}{c}1639 \\
0.822 \\
1631 \\
1083.8\end{array}$ & $\begin{array}{c}1639 \\
0.810 \\
1631 \\
999.3\end{array}$ & $\begin{array}{c}1639 \\
0.809 \\
1631 \\
995.3\end{array}$ & $\begin{array}{c}1633 \\
0.809 \\
1627 \\
943.0\end{array}$ \\
\hline
\end{tabular}

$t$ statistics in parentheses

$* p<0.01, * * p<0.001, * * * p<0.0001$ 
Table 8: Per household and aggregated benefit changes of scenarios for all cities with a population of 50,000 or more in Great Britain 2010-2060.

\begin{tabular}{|c|c|c|c|c|c|c|}
\hline & $\begin{array}{c}\text { Green \& Pleasant } \\
\text { Land }\end{array}$ & Nature@Work & $\begin{array}{c}\text { World } \\
\text { Market }\end{array}$ & $\begin{array}{l}\text { National } \\
\text { Security }\end{array}$ & $\begin{array}{c}\text { Local } \\
\text { Stewardship } \\
\end{array}$ & $\begin{array}{c}\text { Go with the } \\
\text { Flow }\end{array}$ \\
\hline \multicolumn{7}{|c|}{ Aggregate Values in Billion $£$} \\
\hline Undiscounted Value Change & 141 & 284 & $-1,440$ & -597 & 129 & -118 \\
\hline Annuity (50 years) & 2.81 & 5.68 & -28.8 & -11.9 & 2.59 & -2.36 \\
\hline $\begin{array}{l}\text { Net Present Value (H.M. Treasury } \\
\text { standard discounting) }\end{array}$ & 66 & 134 & -676 & -280 & 61 & -55 \\
\hline $\begin{array}{l}\text { Net Present Value (H.M. Treasury, } \\
\text { scenario specific) }\end{array}$ & 66 & 112 & -676 & -341 & 82 & -61 \\
\hline
\end{tabular}

Per Household* Values in $£$

\begin{tabular}{|c|c|c|c|c|c|c|}
\hline Undiscounted Value Change & 9,300 & 18,700 & $-94,700$ & $-39,300$ & 8,500 & $-7,800$ \\
\hline Annuity (50 years) & 185 & 374 & $-1,900$ & -786 & 170 & -155 \\
\hline $\begin{array}{l}\text { Net Present Value (H.M. Treasury } \\
\text { standard discounting) }\end{array}$ & 4,360 & 8,800 & $-44,500$ & $-18,500$ & 4,000 & $-3,650$ \\
\hline Net Present Value (H.M. Treasury, & 4,360 & 7,400 & $-44,500$ & $-22,400$ & 5,400 & $-4,000$ \\
\hline
\end{tabular}

scenario specific)

* Based on the 15.2 million urban households living in the areas included in the extrapolation. 
Table 9: Benefit changes of scenarios for all cities with a population of 50,000 or more in Great Britain 2010-2060 using distributional weights.

\begin{tabular}{|c|c|}
\hline $\begin{array}{c}\text { Green \& Pleasant } \\
\text { Land }\end{array}$ & Nature@Work \\
\hline
\end{tabular}

Undiscounted Value Change

Annuity (50 years)

Net Present Value (H.M. Treasury standard discounting)

Net Present Value (H.M. Treasury, scenario specific)
Aggregate Values in Billion $£$ (using distributional weights)

180
3.6
85

180

3.61

85

85

368

$-1,850$

7.37

$-37.0$

173

146

$-870$

$-870$

$-776$

$-15.5$

$-365$

$-443$

tewardship

Per Household ${ }^{*}$ Values in $£$ (using distributional weights)

Undiscounted Value Change

Annuity (50 years)

Net Present Value (H.M. Treasury standard discounting)

Net Present Value (H.M. Treasury, scenario

specific)

*Based on the 15.2 million urban households living in the areas included in the extrapolation

$\begin{array}{cccccc}11,900 & 24,300 & -122,000 & -51,100 & 10,900 & -10,100 \\ 238 & 485 & -2,440 & -1,020 & 219 & -203 \\ 5,590 & 11,400 & -57,300 & -24,000 & 5,140 & -4,760 \\ 5,590 & 9,580 & -57,300 & -29,200 & 6,930 & -5,240\end{array}$

